\title{
Alternative approaches to measuring concentration in liner shipping
}

\author{
Olaf Merk ${ }^{1} \cdot$ Antonella Teodoro $^{2}$
}

Accepted: 12 February 2022 / Published online: 28 February 2022

(c) The Author(s), under exclusive licence to Springer Nature Limited 2022

\begin{abstract}
Shipping has always had a special relationship with competition law and economics. Even if special competition law regimes for the shipping industry continue to exist, most countries nowadays accept the notion that shipping markets should be more competitive. Competition authorities monitor this in a more or less regular fashion, with various market concentration indexes. The liner shipping industry is peculiar in its widespread cooperation schemes between carriers, in the form of vessel sharing agreements, also known as consortia. Carriers engage in cooperation with all of their major competitors in a system of consortia that is highly interlinked. This brings considerable risks of abuse of market power. Yet, the system of inter-linked consortia has never been systematically mapped, nor do competition authorities appear to monitor them. This article addresses this gap, by proposing alternative indicators, in addition to the traditional industry concentration indexes such as the Herfindahl-Hirschman Index (HHI), that take the reality of consortia into account. Here, five possible alternative indicators are considered: the market share of consortia and independent operators; the share of consortia exceeding market share thresholds; the industry market concentration of consortia; a modified HHI that takes consortia into account; and interlinkages between consortia. We analyse the current state of concentration of liner shipping on the basis of these indicators using a new and unique database that contains deployed ship capacity of container carriers on all of their liner services. Based on this dataset we provide an overview of differences in industry concentration across world regions and developments over time. Traditional indicators show an increase in industry concentration. For example, over the trade corridors to and from Northern Europe, the HHI scores in 2006 ranged from 604 to 2463 , and from 1164 to 4882 in 2021 . The alternative criteria show additional industry concentration. We show that in 2021, 704 out of more than 1500 agreements among carrier consortia had a combined market share of at least $30 \%$, and 102 of them had a combined market share of at least $50 \%$. We also observe that in 2021, the carriers active in alliances operated $85 \%$ of the consortia capacity. Although carriers that are in the same alliance operate most of these consortia, it is also noteworthy that carriers that are not in the same alliance operate a considerable part (24\%) of
\end{abstract}

Extended author information available on the last page of the article 
the consortia. Our calculations of modified Herfindahl-Hirschman Index (MHHI) indexes that take consortia into account show that industry concentration is higher when consortia are taken into account: for example on the trade corridor Northern Europe-North America East Coast, the MHHI has reached the threshold of 2500 points, despite an HHI score of around 1500. In the conclusion of the article, we put forward ways in which these alternative indicators could be used by competition authorities.

Keywords Container shipping · Alliances · Consortia · Vessel sharing agreements · Liner shipping concentration $\cdot$ Market power

\section{Introduction}

The relationship between shipping and competition has always been peculiar. For long periods in history, liner shipping consisted of local or regional monopolies, facilitated by navigation laws that protected national shipping companies rather than promote competition. Even when navigation laws became gradually less protectionist, liner shipping has since 1875 been characterised by cartels, called shipping conferences, that managed to survive for a long time despite strong resistance from shippers and governments (Marx 1953; Ortiz Blanco 2007). Protection of the European oligopoly in liner shipping has been considered to be one of the constituent elements of the post-WW II Atlantic policy consensus on shipping (Cafruny 1987). Liner shipping conferences started to lose relevance in the 1990s, also thanks to changes in regulatory regimes in the US and the EU, following an OECD report that was critical of liner conferences (OECD 2002). However, conferences continue to be allowed in several countries, including transhipment hubs such as Singapore.

Many countries continue to grant a special status to liner shipping in their competition laws, by exempting it from parts of regular competition law and granting it privileges that other sectors do not have. Countries with such shipping-specific block exemptions include Hong Kong, Australia, New Zealand and Chile. The EU has a consortia block exemption regulation in place to facilitate cooperation between liner shipping companies via consortia. Such regulation allows joint negotiation with service providers, such as terminal operators and towage companies, and joint capacity management by consortia. These privileges have come under increased scrutiny since container carriers managed to improve the prices for their services (ocean freight rates) and their profitability in 2020, at least in part thanks to their ability to withdraw ship capacity when demand for container transport slumped in the first half of 2020 .

Despite the shipping-specific privileges, most countries nowadays accept the premise that shipping markets should be competitive. Competition authorities monitor this in a more or less regular fashion, with the regular market concentration indexes that form the standard tools of competition authorities throughout the world. This article argues that these standard tools ignore a specificity of the liner shipping industry, namely the widespread cooperation between carriers, in the form of 
vessel sharing agreements (also called consortia) and alliances that can be considered bundles of such agreements, both of which have become more important over time (ITF 2018, 2019). Consortia and alliances are used by carriers to increase the utilisation rate of their vessels: sharing vessels makes it possible for carriers to offer a (shared) service network that they would not be able to offer on their own. At the same time, the emergence of consortia and alliances has reduced choice for shippers and increased the buying power of carriers, and thus the oligopsony risks vis-à-vis ports and port service providers. So consortia could entail, as it does, considerable risks of abuse of market power that conventional market concentration indexes could miss. We propose alternative approaches to measuring concentration in liner shipping that take account of the reality of shipping consortia and alliances. Such alternative measurement approaches could help competion authorities to identify and mitigate abuses of market power in liner shipping.

\section{Existing approaches and their limitations}

One of the most frequently used indicators to estimate industry concentration is the market share of the largest companies operating in the market, in particular the fourfirm concentration ratio $\left(\mathrm{CR}_{4}\right)$, i.e., the cumulative market share of the four companies with the largest market share. Another indicator frequently used in competition assessments is the Herfindahl-Hirschman Index (HHI), calculated by squaring the market share of each competing firm in an industry and then summing the resulting numbers. Sometimes the calculation is made on a more limited set of firms, e.g. the largest 50 companies, if it is challenging to obtain data for all the companies, and also because the squared market share of the smallest firms would hardly change the value of the index. Scores can range from 0 to 10,000 points, but can also be expressed as fractions ranging from 0 to 1.0: an index of 0.5 is equivalent to 5000 points. A market with an HHI higher than 2500 points is considered to be highly concentrated under the US merger guidelines (US Department of Justice and FTC, 2010), whereas EU merger guidelines indicate that the European Commission is unlikely to identify horizontal competition concerns in a merger with a post-merger HHI between 1000 and 2000 and a delta (change in HHI) below 250, or a merger with a post-merger HHI above 2000 and a delta below 150 (EC, 2004).

Various academic studies have applied the $\mathrm{CR}_{4}$ and $\mathrm{HHI}$-indicators to liner shipping. All of them define market shares in terms of capacity shares, which is different from the application in many other industries where market shares are defined in terms of revenues. This difference can be explained by the lack of data on revenues for carriers per trade route. A fairly common approach is to apply the $\mathrm{CR}_{4}$ and $\mathrm{HHI}$ to the global container shipping market (see e.g., Goulielmos 2017; Luo et al. 2014; Sys 2009). The same indicators are also applied in various studies that deal with specific liner shipping markets, for example on the main East-West trades (Hirata, 2017) and the Korean liner shipping industry (Ha \& Seo, 2013). Specialised maritime consultants sometimes also made similar assessments. However, there are no studies that assess the development of these market concentration indexes for all different trade routes comprehensively over 
time. This study will fill that gap, in addition to proposing five new alternative indicators for assessing market concentration.

Competition authorities have applied competition assessments of the liner shipping market using analysis of market shares. In the EU's assessments of mergers in liner shipping, the combined market shares of the alliances and consortia of the merging companies are taken into account (see for example EC 2016a, 2016b, 2017a, 2017b), but not the HHI scores. The analysis is specific to the companies that merge and only takes place at the moment of the merger decision; there is no regular, comprehensive assessment on the competitive effects of consortia.

The existence of consortia is generally not taken into account in these analyses. An illustration of this neglect is the content of the document that is meant to justify the extension until 2024 of the EU Consortia Block Exemption Regulation (EC, 2019): it admits to lacking data on consortia that cover EU trades and the market shares of these consortia, despite the fact that the regulation contains a market share threshold of $30 \%$ above which the regulation no longer applies. The system of inter-linked consortia has never been systematically mapped, nor do competition authorities appear to monitor it. This likely leads to underestimation of market concentration in liner shipping, similar to underestimations of market concentration in the presence of "common ownership".

Common ownership refers to situations in which one or more owners of a company also own shares in one or more competing companies in the same industry (OECD, 2017). The basic insight is that concentration could be underestimated if firms are supposed to behave fully independently, despite their underlying ownership. Common ownership can be limited to a single partial ownership interest, in a single acquired form by a single acquiring firm. However, the economic framework of common ownership has also been extended to the case of joint ventures, that is, entities that are owned by and compete with a number of competing firms. Joint ventures may be horizontal, vertical or both. A horizontal joint venture is a jointly owned entity whose parents compete with the venture and each other. A vertical joint venture is a jointly owned entity whose parents supply input to the venture, or produce outputs using an input produced by the venture. Joint ventures also can involve both vertical and horizontal elements. For example, a joint venture may be jointly owned by firms that are vertically integrated and compete with the venture and each other in at least one of the markets (O’Brien and Salop 2015).

Consortia could be considered as vehicles for what has been referred to in the competition literature as "common ownership", applied to container shipping. Consortia could be considered joint ventures of two or more container carriers that pool ships to provide a jointly operated shipping service. On some trade corridors, carriers provide all their capacity via consortia, on other corridors consortia compete with services provided by carriers individually, and-more rarely—on some other corridors all services are offered by carriers individually. 


\section{Alternative indicators}

New approaches to measuring competition in liner shipping should take the reality of consortia into account, because the emergence of consortia is not simply a development that takes place in parallel with industry consolidation, but has arguably its own dynamics and could - in combination with consolidation-have more profound impacts than traditional indicators, or other metrics such as the reduction of the number of shipping companies (see Hoffmann and Hoffmann, 2021) could capture.

This approach intends to capture industry concentration on the shipping-side. The definition of the relevant market is the maritime trade corridor between two sets of ports, as constituted by actual liner shipping services. Container carriers are also active in other markets, such as container terminals and logistics services, but these fall outside the scope of this article. Here, five possible alternative indicators are proposed, covering: the market share of consortia and independent operators; the share of consortia exceeding market share thresholds; the industry concentration of consortia; a modified HHI that takes consortia into account; and interlinkages between consortia. These are explained briefly below.

\subsection{Market share of consortia and independent operators}

An elementary but essential indicator is the share of liner shipping capacity provided by consortia in the different trade corridors. Considering lack of data on revenues per trade route by carriers, market shares are based not on revenues but on shipping capacity. Whereas market shares of alliances are regularly reported by specialized maritime consultants, this is not the case for shares of consortia. A closely related indicator concerns the market share of independent operators on the different trade corridors. Independent operators on a trade corridor are here defined as containership operators that do not partake in consortia (or an alliance) on that trade corridor. They might operate in consortia on other trade corridors and on the latter corridors are not considered as independent operators.

\subsection{Share of consortia exceeding combined market share thresholds}

The idea behind this indicator is to assess how many of the consortia operating on a trade route exceed a certain defined market share. Such an indicator would be closely linked to policies in certain jurisdictions. For example, the EU Consortia Block Exemption Regulation defines a 30\% threshold for consortia: if the market share of consortia exceeds this threshold the CBER no longer applies to this consortium. We define consortia market share here in the same way as in CBER, namely as the total market share of consortium members, that means "the total volumes of goods carried by the member in the relevant market shall be taken into account irrespective of whether those volumes are carried within the consortium in question, within another consortium to which the member is a party, or outside any consortium, independently by the member on its own, or on third party vessels" (EC 2009). 
In this way, the assessment takes account of the interlinkages between carriers and consortia. The consequence of this is that the sum of the combined market shares on a trade route can be more than $100 \%$. In this article, we assess the share of consortia exceeding combined market share thresholds of $30 \%$ and $50 \%$. We are able to monitor the number of consortia that exceed the threshold and also the shipping capacity that this represents.

\subsection{Consortia market concentration index}

In order to assess the industry concentration of consortia (including alliances), we developed a Consortia Market Concentration Index (CMCI), both at the level of trade corridors and at the global level. This Index is closely related to the first two alternative indicators described above and it is based on four components:

1. Percentage of deployed capacity operated by consortia: the ratio between the capacity deployed by consortia (and their members), and the total capacity deployed by all shipping lines.

2. Percentage of number of services operated by consortia (or their members): the ratio between the number of services operated by consortia (and their members) and the total number of services on offer.

3. Percentage of shipping lines operating as part of a consortium: the ratio between the number of shipping lines operating as part of a consortium and the total number of active shipping lines on a trade corridor.

4. Highest combined consortia market share: the highest combined market share of any consortium operating on the trade corridor, using the definition of combined market share provide above.

The CMCI is the average of the four components multiplied by 100 . The CMCI can, therefore, have values between 0 and 100, with 0 representing a market where no consortia operate, and 100 representing a market in which all the services are operated by one or more consortia and where the largest combined consortia market share equals $100 \%$. From the CMCI at the trade corridor level, we have then derived the CMCI Global, which aims to describe the level of consortia industry concentration at the global level for any given year in the time-series. The MCI Global has been calculated as the weighted average of the MCI at the trade corridor, weighted by the capacity deployed, so that industry concentration on busy trade routes have higher weights than trade routes with only limited traffic (deployed capacity). We have also developed a CMCI Deepsea indicator (for intercontinental container transport) and a CMCI Shortsea (for intracontinental container transport).

\subsection{Modified HHI to take account of common ownership}

In order to measure market concentration in the presence of common ownership, the modified Herfindahl-Hirschman Index (MHHI) was developed by Bresnahan and Salop (1986) and generalized by O'Brien and Salop (2015). It adapts the typical 
measure of market concentration (HHI) to take into account ownership links among competing firms.

The MHHI consists of two elements: the standard HHI and an "MHHI delta". The MHHI delta depends on the amount of control or influence that an investor has in a firm and its competitors, as well as the corresponding financial interests of the firm and its competitor firms. All else equal, a higher degree of control or influence by common investors would translate into a stronger link between firms and therefore a higher MHHI, implying higher concentration in an industry. In a situation with no common or cross ownership ties, the MHHI delta would be zero, and the MHHI would be equivalent to the standard HHI. O'Brien and Salop (2015) identify different cases of corporate control and develop a formula for each situation to calculate the MHHI delta. At the one extreme is the case of no control at all (silent financial interests); at the other extreme is total control via mergers. In between are various scenarios of partial control. In these scenarios, the decision makers of the acquired (or partially acquired) firm take into account the fact that certain of its shareholders hold financial interests in competing firms in addition to the interests in the acquired firm. Partial controls scenarios that are considered are:

- Fiduciary obligation in which control by the acquiring firm is constrained by legal rules that create an obligation to serve the interests of minority shareholders;

- Coasian joint control, in which the managers of the acquiring firm try to maximize the joint profits of both the acquired firm and the acquiring firm. In this way, they make the same decisions that they would if they were actually merged.

- One-way control, which refers to a scenario in which the acquiring firm has enough power over the acquired firm to force it to maximize joint profits and not secretly cheat.

- Proportional control, a scenario in which managers of the acquiring firm take the shareholders' interests into account in proportion to their financial interests in the acquired firm, rather than trying to maximize joint profits.

Consortia are made up of at least two carriers, which means that no carrier has full control over the consortium in which they participate. There are no silent financial interests in consortia. This means that consortia generally fall within the partial control scenarios. Considering that all major carriers deploy the majority of their ship capacity in consortia, one could argue that carriers' control of consortia resembles Coasian joint control and to some extent resembles an actual merger. At the same time, consortia are also the expression of a compromise between different visions of the participating carriers, in relation with the capacity that they contribute to the consortium. For this reason, we assume that the condition of proportional control applies to consortia. The MHHI delta related to proportional control is provided in O'Brien and Salop (2015) and is as follows:

$$
\Delta=\left(\beta+\beta /\left((1-\beta)^{2}+\beta^{2}\right)\right) s_{1} s_{2}
$$


In this formula, the delta is caused by a partial ownership transaction in which firm 1 obtains a financial interest in firm 2 that entitles it to a fraction $\beta$ of the profits of firm 2 , and the two firms have pre-acquisition market shares of $s_{1}$ and $s_{2}$, respectively. The fraction $\beta$ stands for the fraction of the profits of the acquired firm that the acquiring firm is entitled to. In the context of consortia, $\beta$ stands for the fraction of the capacity that the carrier contributes to the consortium, which generally represents the fraction of the profits of the consortium that the carrier is entitled to. In the case of joint ventures, in line with O'Brien and Salop (2015), there will be a similar component of the MHHI delta for each partial ownership interest, and these are aggregated to an overall delta. More details on how the MHHI has been calculated in the context of the liner consortia is provided in Annex 1.

\subsection{Interlinkages between carriers}

This indicator seeks to describe patterns related under which carriers cooperate in consortia. There is considerable literature on shipping alliances that conceals the fact that carriers also cooperate in consortia, with carriers that are not necessarily part of the same alliance. By mapping the interlinkages between carriers via their consortia, it is possible to establish if cooperation in consortia takes place mostly by carriers in the same alliance.

\section{Description of database}

The main source of this study is the MDS Transmodal Consortia \& Alliances Database, a sub-product of a larger database, the MDST Containership Databank. This database is built and maintained by the maritime consultancy MDS Transmodal and it contains detailed information on the world's container fleet; i.e., of some 9,000 container vessels. In more detail, for every container vessel in service, the database has over 35 fields of information including operator, service, route, TEU, service frequency, and port rotation. Next to service deployment, the database provides physical attributes and details of the container vessels. It also includes information about vessels on order and vessels removed from the commissioned fleet. Service deployment of individual vessels in the fleet changes frequently, therefore, the database is updated on a continuous basis. The database, in its current format, has been produced since 2006. The MDST Containership Databank is also used by UNCTAD to produce (in collaboration with MDST) the Liner Shipping Connectivity Index (LSCI) and by the World Bank to produce the Logistics Performance Index (LPI).

For any given trade corridor, the MDST Consortia \& Alliances Database has allowed us to identify the services offered by the shipping lines operating in consortia, in alliances or as independent carriers and then to estimate their combined market shares. The MDST Consortia \& Alliances Database has been developed following the steps described below: 
- Starting from the MDST Containership Databank that contains the port-toport service data per ship (with their IMO number), we have grouped the port pairs into trade corridors (e.g., a service calling, among others, at the port of Shanghai and at the port of Rotterdam, has been allocated to the East China Sea-North Europe trade corridor). In order to ensure a sufficient level of detail in our analysis, we have split the world into 20 maritime regions, with the combinations amongst them being defined as 'trade corridors' (the complete list of trade corridors and countries/country areas included in them is shown in Annex 2). For 2021, we identified 171 unique trade corridors, of which 154 are served by at least one consortium.

- For each vessel deployed on any given service, the MDST Containership Databank indicates the name(s) of the shipping line(s) that operate them. This information has allowed us to identify the services operated by more than one shipping line, and to assume an agreement in place amongst them. A list of vessel sharing agreements signed by the shipping lines is not publicly available. We believe, however, that shipping lines operating different vessels deployed on the same service can be de-facto considered as part of a Vessel Sharing Agreement (VSA). In the 154 trade corridors where at least one consortium is active, we identify 1500 joint services amongst the shipping lines.

- For each trade corridor, we have also identified the shipping lines operating in alliances.

- From the previous steps, we have been able to identify 'who is doing what, where'. Based on this, we have then estimated the different concentration indexes described below.

In our analysis we have focused on the second quarter of each year, as it can be considered the quarter that is generally the least affected by seasonality. However, the databases we used to produce the MCI cover all the quarters of 2006-2021, which allowed us to extend the calculations to the other quarters as well.

\section{Main findings}

This section assesses if the use of the alternative indicators would bring added value in terms of a deeper understanding of industry concentration in liner shipping. As such, it provides a brief overview of the global values of the main indicators and their development over time (2006-2021). Within the space constraints of this article, it is not possible to provide a comprehensive and comparative overview across regions. We instead focus on the case of Northern Europe to illustrate the potential use of the alternative indicators. Rather than provide results for all the 20 trade corridors to and from Northern Europe, we focus on a selection of main trade corridors: the intra-North Europe corridor, the North Europe-Mediterranean corridor, North Europe-North America East Coast, North Europe-South China Sea and North Europe-South America East Coast. 


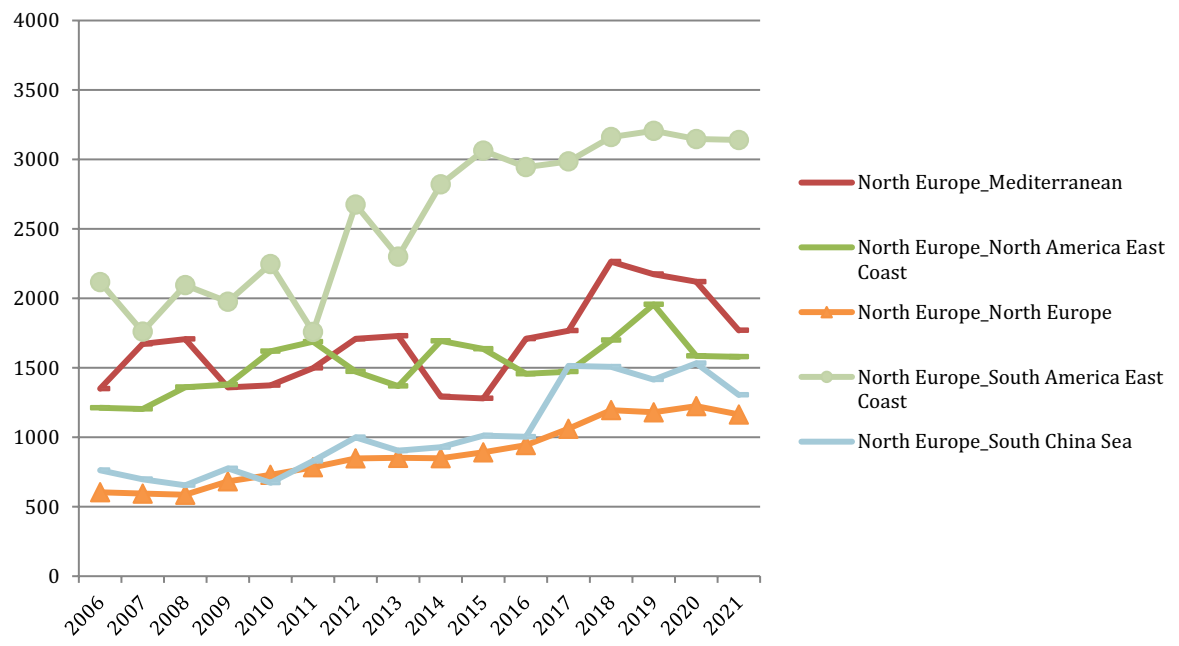

Fig. 1 HHI scores on selected North Europe trade corridors

\subsection{Traditional industry concentration indicators}

The industry concentration ratios of liner shipping at the global level have often been described as fairly moderate. However, it is misleading to look at the global level; one should instead focus on the level of trade corridors (Haralambides, 2019). When focusing on industry concentration at the level of trade corridors, a more pronounced picture arises. On 53 out of 154 trade corridors in which we identify at least one consortium, the HHI in 2021 exceeded 2500 points, the threshold above which a market is considered highly concentrated. This is the case for 7 of the 20 trade corridors to and from Northern Europe. The market concentration on these trade routes, to and from Northern Europe, has clearly become more intense: the 2021 HHI scores on 18 out of 20 trade corridors to and from Northern Europe are considerably higher in 2021 than in 2006, including the trade corridors selected for our analysis (Fig. 1). The range between the lowest and highest score in 2006 was 604 to 2463 points; this was 1164 and 4882 in 2021 (not taking into account the North-Europe-East Africa trade corridor that can be considered an outlier).

\subsection{Capacity deployed by consortia and independent operators}

The number of consortia has increased substantially over 2006-2021, together with the capacity they operate. In 2006, around $31 \%$ of the global containership capacity was operated in consortia; this was $49 \%$ in 2021 . Over the same period, the share of capacity operated by shipping lines that are members of alliances increased from $22 \%$ in 2014 to $42 \%$ in 2021 . This implies that in addition to mergers and acquisitions, further market consolidation has been occurring in the liner shipping industry through the formation of consortia amongst the biggest shipping lines. 


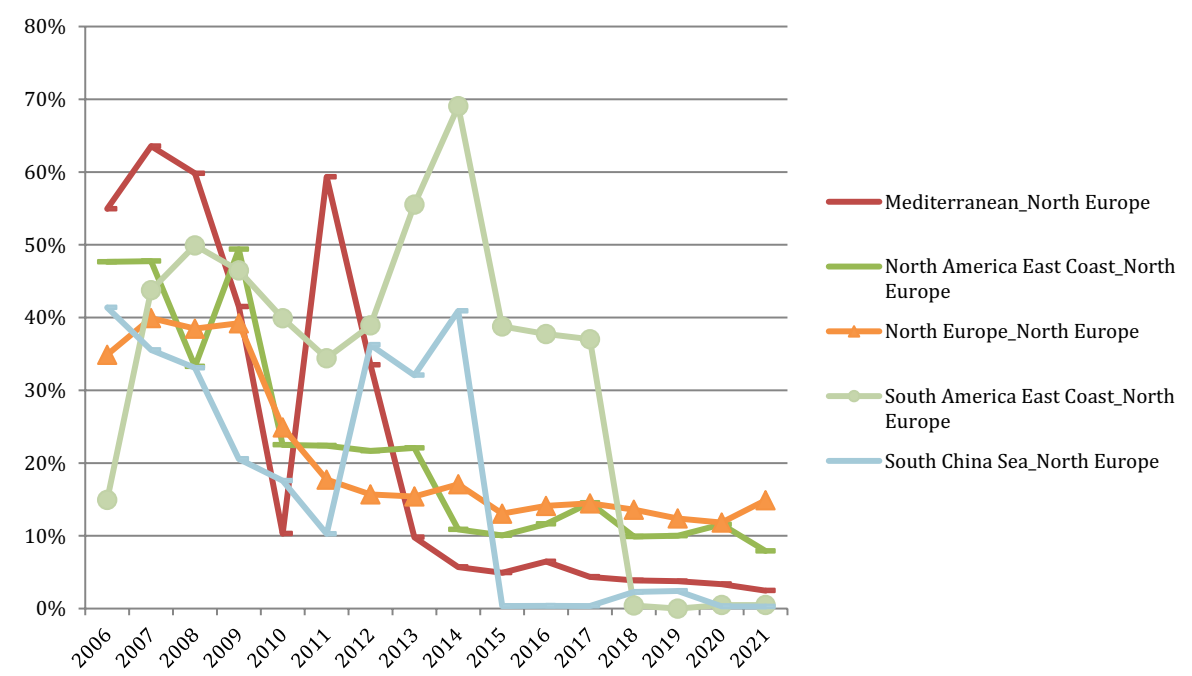

Fig. 2 Capacity share of independent operators on selected North European trade corridors

A different way of looking at the same phenomenon is by assessing the share of independent operators. In 2021, the market share of independent operators exceeded $10 \%$ in only 24 out of the 154 unique trade corridors, where at least one consortium was active. In terms of demand, these trade corridors are estimated to account for circa $12 \%$ of global trade. On most Northern European trade corridors, the share of independent operators has decreased steadily: in 2006, on all 20 corridors independent operators had a market share that exceeded 10\%; in 2021 this was the case for only 3 out of 20 trade corridors: the corridors with Atlantic Islands, West Africa and the intra-North European corridor. For our selected North European corridors, the decline of the share of independent operators took place in the mid-2010s (Fig. 2). At the same time, Fig. 2 also illustrates that there can be significant fluctuations from year to year, which underlines the need for adequate and regular monitoring of industry concentration by competition authorities.

\subsection{Share of consortia exceeding combined market share thresholds}

In 2021, 704 out of more than 1500 agreements among carrier consortia had a combined market share of at least $30 \%$, and 102 of them had a combined market share of at least $50 \%$. In almost all trade corridors-142 out of 154, representing $95 \%$ of the global capacity - we identified at least one consortium with a market share of $30 \%$ or more in 2021 . We also observed a clear increase in the number of trade corridors where at least one of the consortia exceeded the $30 \%$ threshold. In 2006 , consortia with at least $30 \%$ of market share were present in only 39 out of 146 trade corridors identified for 2006; on these routes $21 \%$ of the global trade was moved. Note that this is the combined market share threshold; this means it includes the capacity operated in the consortium in question, plus the capacity 


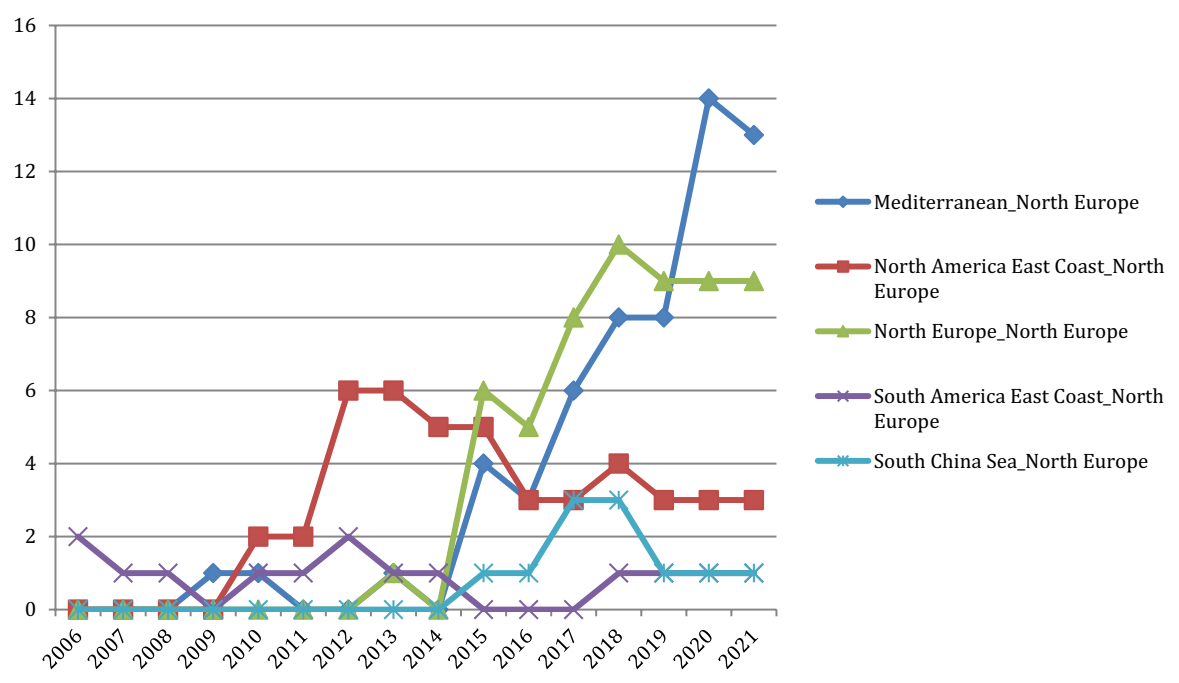

Fig. 3 Number of consortia exceeding 30\% market share threshold in selected North Europe corridors

within another consortium to which the member is a party, plus the capacity outside a consortium on the member's own or on third party vessels.

The trade corridor with the biggest number of consortia exceeding $30 \%$ of market share in 2021 was the intra South East Asia corridor, where we identified 40 consortia (out of 78 ) with a combined market share of at least $30 \%$. In trade corridors to and from Northern Europe, 18 out of 20 corridors had one or more consortia that exceed a combined market share of $30 \%$ in 2021 ; this was the case only for 6 out of 20 corridors in 2006. There has been a remarkable increase in the number of intra-Europe consortia exceeding the $30 \%$ combined market share threshold since 2014 (Fig. 3). In other words, the sum of the combined market shares on a trade corridor can be larger than $100 \%$.

\subsection{Consortia Market Concentration Index}

The Consortia Market Concentration Index at the global level increases over 2006-2021 from a score of 48 in 2006 to 74 in 2021. The most significant increase takes place in 2015, mainly due to the formation on the $2 \mathrm{M}$ Alliance between Maersk Line and Mediterranean Shipping Company (MSC). The impact that this has had on the level of market consolidation is most noticeable in the deep-sea market, but also the short sea market shows increasing market concentration in 2015 (Fig. 4). The Consortia Market Concentration Index shows more fluctuations at the level of trade corridors. An analysis of selected Northern European trade corridors confirms the general trend of higher concentration since 2014 , clearly visible in all of the selected corridors, whereas the development prior to 2014 is less uniform (Fig. 5). 


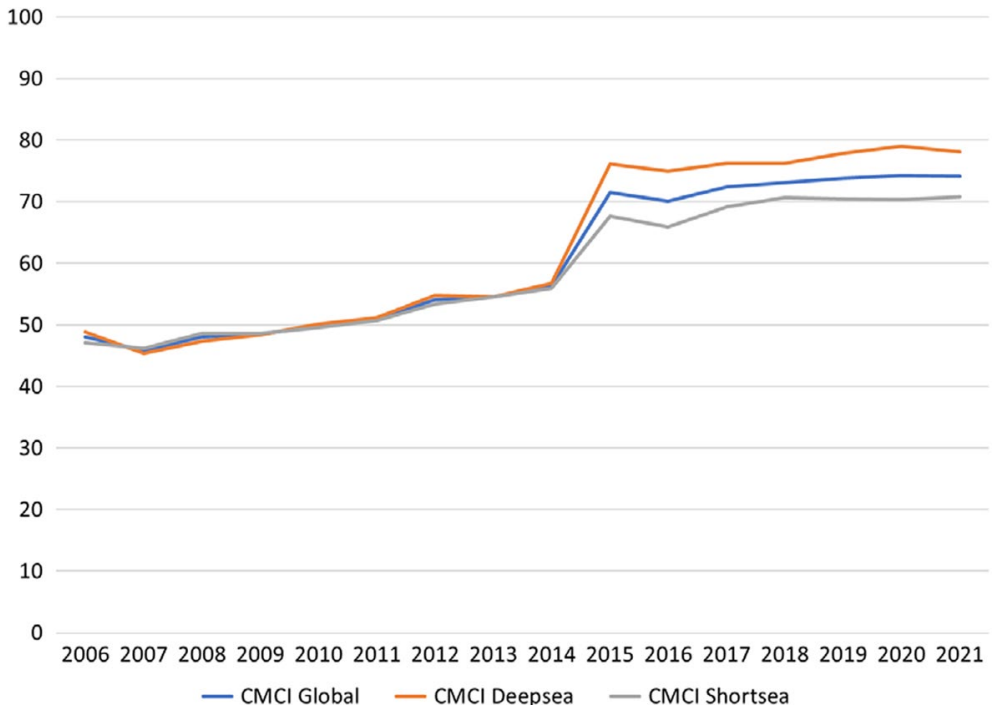

Fig. 4 Development of Consortia Market Concentration Index at global level

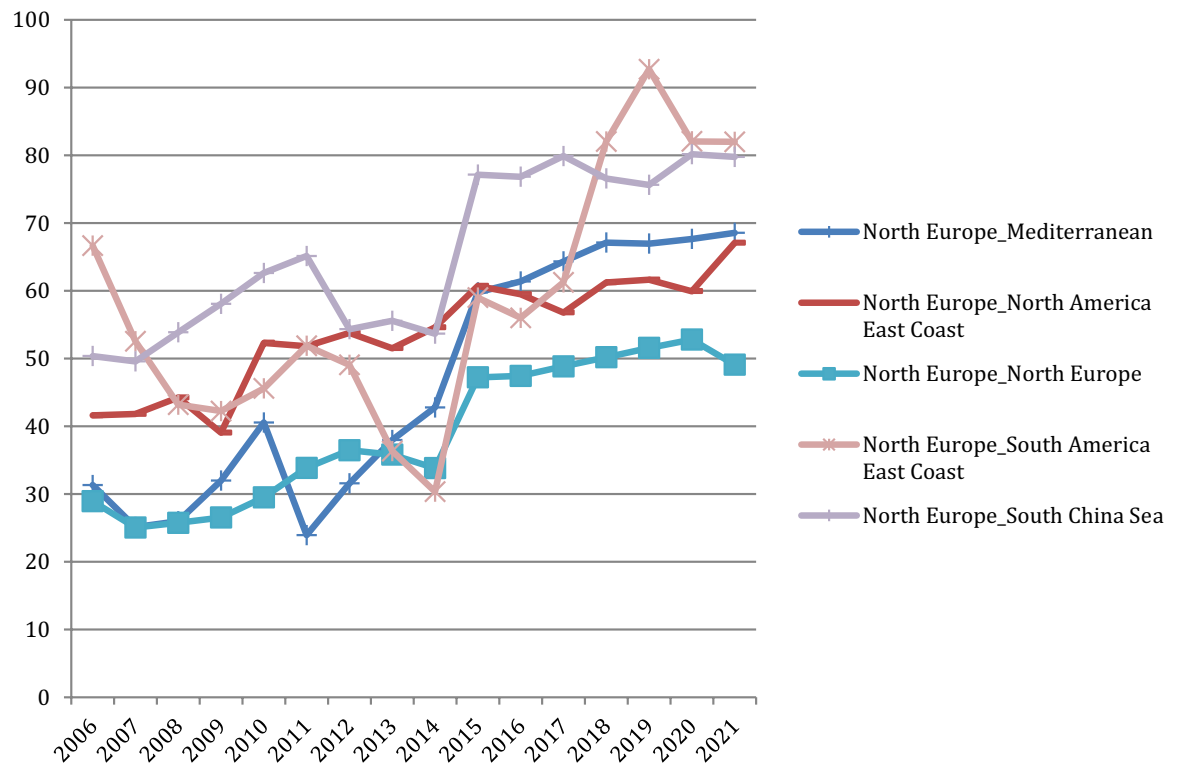

Fig. 5 Development of Consortia Market Concentration Index of selected North Europe trade corridors

\subsection{Modified HHI}

The calculation of the MHHI on two selected trade corridors shows the increased relevance of consortia when determining industry concentration of liner shipping. 


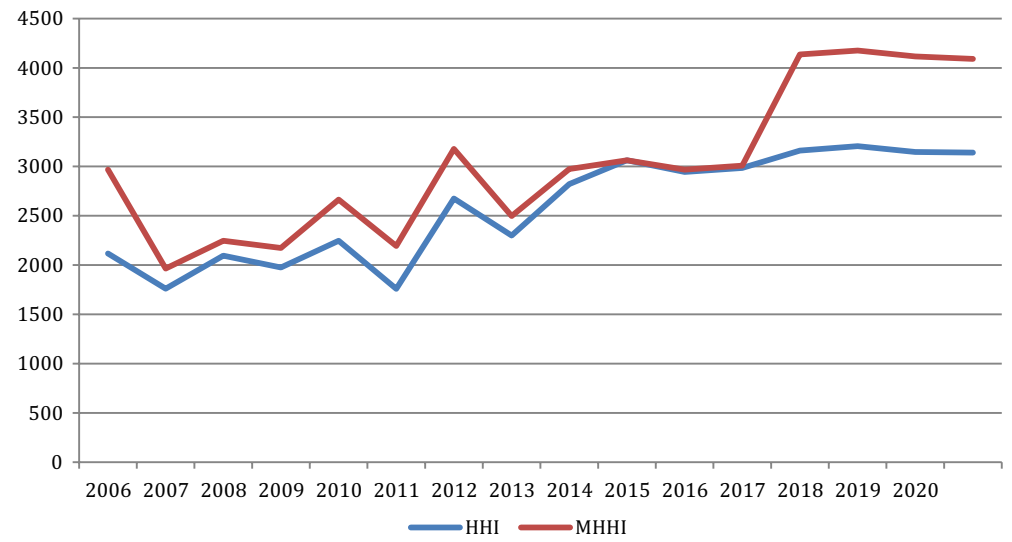

Fig. $6 \mathrm{HHI}$ and Modified HHI on the North Europe-South America East Coast trade corridor

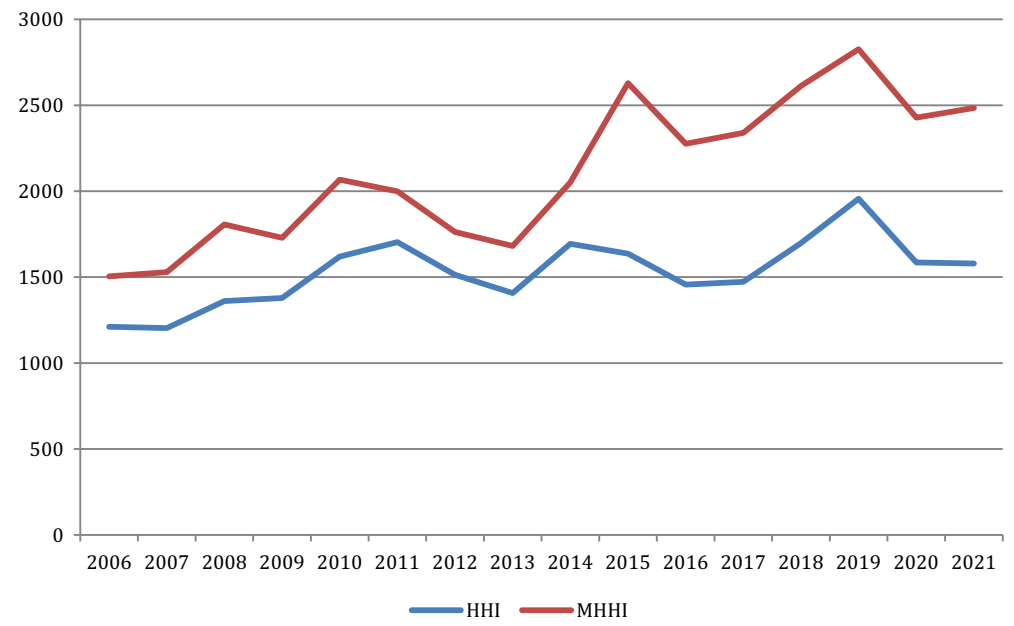

Fig. $7 \mathrm{HHI}$ and Modified HHI on the North Europe-North America East Coast trade corridor

On the North Europe-South America East Coast corridor, the scores of the HHI and MHHI are more or less similar between 2007 and 2017 (Fig. 6), which indicates that the presence of consortia did not significantly alter industry concentration on this trade corridor. After 2017, a substantial difference between HHI and MHHI appeared, of around 1,000 points, suggesting that the trade corridor has become substantially more concentrated due to consortia operations. On the North Europe-North America East Coast, there has been a difference of approximately 250 points between the HHI and MHHI between 2006-2014; this difference increased significantly after 2014 to around 900 points, due to changes in 
consortia and the emergence of new bundles of consortia (alliances) (Fig. 7). The MHHI on this trade corridor has reached the threshold of 2500 points, despite an HHI score of around 1500.

\subsection{Interlinkages between carriers}

Consortia have increasingly become tools for the largest carriers that cooperate in alliances. Since 2016, the majority of the capacity operated in consortia is in the hands of the carriers that also operate in alliances. In 2021, carriers that operate in alliances operate $85 \%$ of the consortia capacity. Although carriers that are in the same alliance operate most of these consortia, it is also noteworthy that carriers that are not in the same alliance operate a considerable part (24\%) of the consortia (Fig. 8). The share of consortia operated by carriers that are not in one of the three global alliances is small (14\%) in 2021, unlike the period 2006-2014 when this category made up the majority of the consortia capacity.

Our analysis shows that carriers with many consortia agreements with carriers outside their own alliance are Maersk, MSC, Hapag Lloyd, ONE and CMA CGM. On the other hand, carriers like Yang Ming and HMM are fairly "loyal" to their alliance partners and are engaged in few consortia with carriers that are not in the same alliance. In a way, carrier cooperations like COSCO-ONE, CMA CGMHapag Lloyd and MSC-Hapag Lloyd act as bridges between the three global alliances (Table 1).

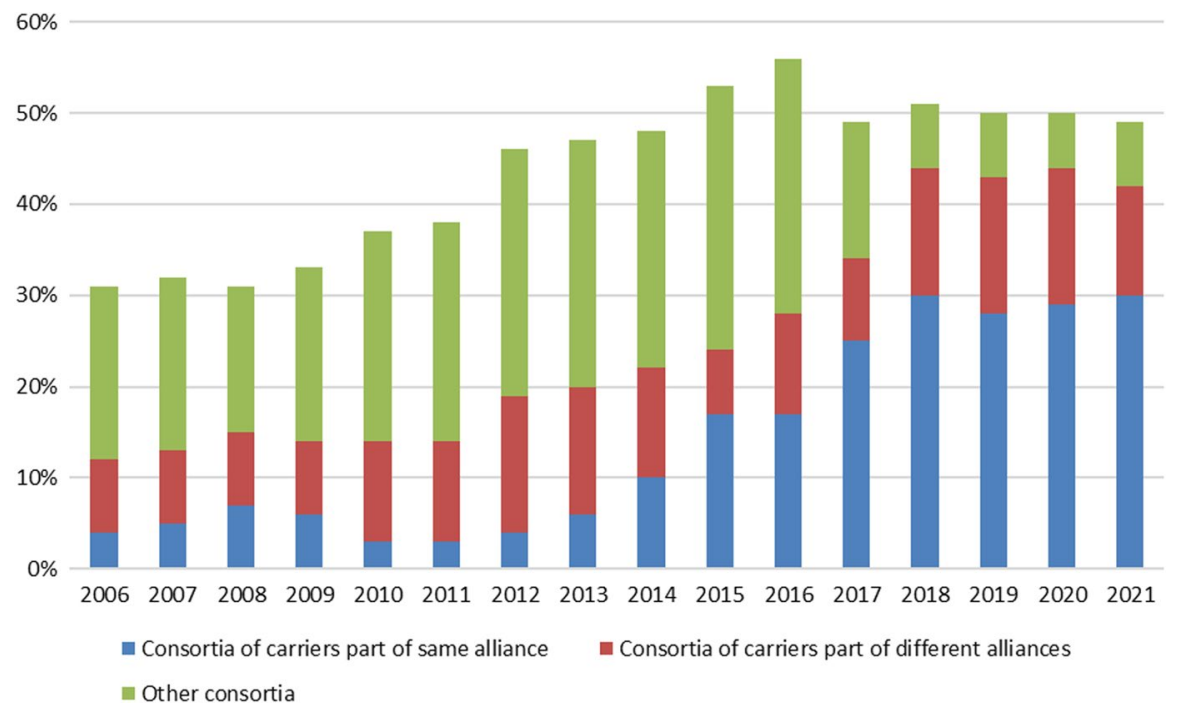

Fig. 8 Market share of different sorts of consortia (2006-2021) 


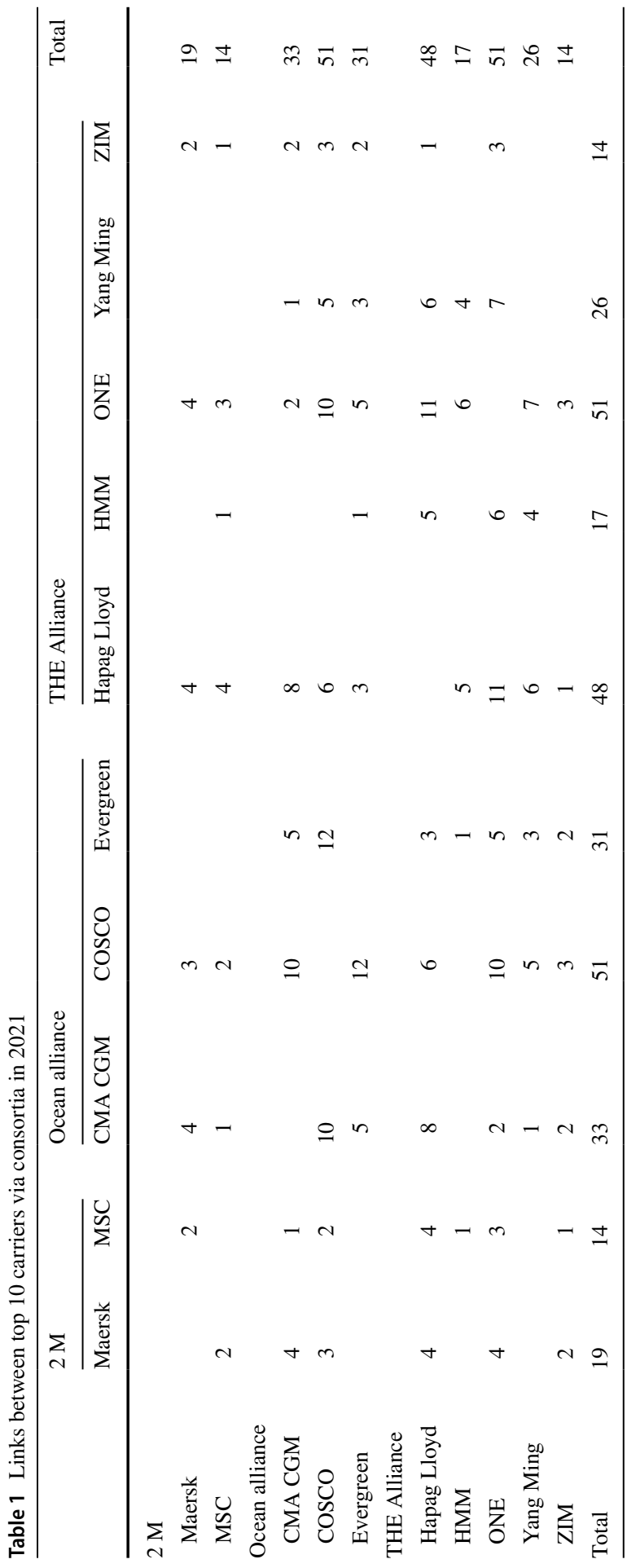

称 


\section{Conclusions and policy relevance}

Traditional tools to measure industry concentration in liner shipping, widely discussed in the academic literature, and to a certain extent applied by competition authorities, are assessments based on market shares of operators, such as the CR4 and HHI. An assessment that uses these indicators -using also a relevant market definition that is broadly defined-will conclude that the industry concentration of liner shipping is still fairly moderate, even if various trade corridors can be considered highly concentrated and even if the majority of trade corridors have become more concentrated over the last decade. The database that we created, and described above, can help to provide a comprehensive picture of the development of industry concentration of liner shipping operators.

We argue that an assessment of industry concentration in liner shipping is highly incomplete if it does not take consortia and alliances into account. In 2021, $86 \%$ of the global containership capacity was operated by the top 9 carriers. They work together in three global alliances and in the majority of the more than 1500 consortia agreements that we identified. In the same year, $49 \%$ of the ship capacity was operated by consortia, of which $32 \%$ was operated by alliances.

The alternative industry concentration indicators that we propose here capture the effect of the proliferation of consortia. We showed that in 2006, independent operators on North Europe corridors had a combined market share of more than $10 \%$ on all 20 corridors; in 2021 this was the case for only 3 out of 20 trade corridors. Almost all trade corridors throughout the world (142 out of 154 trade corridors) have at least one consortium with a market share of $30 \%$ or more in 2021 ; this was only 39 out of 146 trade corridors in 2006. The Consortia Market Concentration Index that we developed shows a strong increase in 2015, both in the deep-sea and short sea market. The growing relevance of consortia in assessing industry concentration in liner shipping is also illustrated by the rapid increase of MHHI in recent years on selected trade corridors, as calculated in this article. These MHHI values also show that liner shipping is much more concentrated than expressed by the traditional indicators, like the HHI. Such indicators could help competition authorities among other things to assess if ports are increasingly confronted with oligopsony of carriers operating in consortia.

Finally, our alternative indicators facilitate our understanding how of consortia help to link carriers that operate in different alliances. Carriers that are not in the same alliance work together in a considerable share $(24 \%)$ of the consortia. Consortia between pairs of carriers in different alliances could act as bridges between the three global alliances. This is important when reflecting how carriers have been able to implement their remarkable "capacity management" over recent years, and in particular during the economic lockdowns that characterized the Covid-19 crisis.

We think that our alternative market concentration indicators-in addition to existing indicators-can help policy-makers to improve scrutiny of competition in liner shipping. Our database provides the possibility to assess the development of market concentration since 2006, taking into account the emergence of 
consortia and alliances. As such, it could be particularly helpful for jurisdictions that have provided the liner shipping industry with block exemptions from competition law, during evaluations of those exemptions, but also simply to monitor in the meantime.

There are many possible extensions and applications of the work presented here. Potential future work could include a comprehensive overview of the state of market concentration in liner shipping, at a global level and in specific regions. It would also be possible to link the market concentration indicators to the development of prices and service quality of liner shipping in different regions, or on specific trade corridors. This would make it possible to assess the impacts of the increased market concentration in liner shipping and have a more informed discussion on ways to address them.

\section{Annex 1: Details on calculation of the MHHI for liner shipping}

We applied the following rules for calculating the MHHI:

- No consortia on the trade corridor: no MHHI deltas, so the standard HHI applies.

- In case a consortium competes with individual operators that are not in the consortium: consider the market share of the consortium instead of the operators in the consortium. So a market of operator 1 and consortium of operators 2 and 3 , implies $\mathrm{HHI}=s_{1}{ }^{2}+s_{\text {cons }}^{2}$.

- When a consortium competes with operators that also participate in the consortium: consider the market share of the consortium and the market share of the operators that operate independently and add a MHHI delta for the operator that operates independently and is in the consortium. For example: operators 1 and 2 both operate $50 \%$ of the capacity on a corridor, but operator 1 deploys all its capacity in a consortium in which operator 2 deploys $40 \%$ of its capacity; operator 2 operates $60 \%$ of its capacity independently $\left(s_{2}\right)$. This gives the following $\mathrm{MHHI}=s_{\text {cons }}{ }^{2}+s_{2}{ }^{2}+\left(\beta+\beta /\left((1-\beta)^{2}+\beta^{2}\right)\right) s_{2} s_{\text {cons }}$ (where $s_{\text {cons }}$ is $70, s_{2}$ is 30 and $\beta$ is $20 / 70$ as this represents the share of the consortium capacity operated by operator 2 ).

- When a consortium competes with another consortium that has partly the same consortium members: take the market shares of the two consortia and add a MHHI delta that expresses the overlapping share. For example: services are offered by two consortia: consortia 1 with market share of $60 \%$ (equally split by operator 1 and 2) and consortia 2 with market share of $40 \%$ (equally split by operator 1 and 3 ). This gives the following $\mathrm{MHHI}=s_{\text {cons, } 1}$ $2^{2}+s_{\text {cons }, 2} 2^{2}+\left(\beta+\beta /\left((1-\beta)^{2}+\beta^{2}\right)\right) s_{1} s_{\text {cons }, 2}$ (where $s_{\text {cons }, 1}$ is $60, s_{\text {cons }, 2}$ is $40, s_{1}$ is 30 (the share of operator 1 operated outside consortium 2) and $\beta$ is $20 / 40$ as this represents the share of the consortium 2 capacity operated by operator 1). 


\section{Annex 2: Unique trade corridors in 2021}

Arabian Gulf to/from Arabian Gulf

Atlantic Islands to/from Atlantic Islands

Australasia \& Oceania to/from Australasia \& Oceania

Caribbean \& Central America to/from Arabian Gulf

Caribbean \& Central America to/from Australasia \& Oceania

Caribbean \& Central America to/from Caribbean \& Central America

East Africa to/from Arabian Gulf

East Africa to/from Australasia \& Oceania

East Africa to/from East Africa

East China Sea to/from Arabian Gulf

East China Sea to/from Australasia \& Oceania

East China Sea to/from Caribbean \& Central America

East China Sea to/from East Africa

East China Sea to/from East China Sea

Indian Subcontinent to/from Arabian Gulf

Indian Subcontinent to/from Australasia \& Oceania

Indian Subcontinent to/from Caribbean \& Central America

Indian Subcontinent to/from East Africa

Indian Subcontinent to/from East China Sea

Indian Subcontinent to/from Indian Subcontinent

Mediterranean to/from Arabian Gulf

Mediterranean to/from Atlantic Islands

Mediterranean to/from Australasia \& Oceania

Mediterranean to/from Caribbean \& Central America

Mediterranean to/from East Africa

Mediterranean to/from East China Sea

Mediterranean to/from Indian Subcontinent

Mediterranean to/from Mediterranean

North America East Coast to/from Arabian Gulf

North America East Coast to/from Australasia \& Oceania

North America East Coast to/from Caribbean \& Central America

North America East Coast to/from East China Sea

North America East Coast to/from Indian Subcontinent

North America East Coast to/from Mediterranean

North America East Coast to/from North America East Coast

North America West Coast to/from Arabian Gulf

North America West Coast to/from Australasia \& Oceania

North America West Coast to/from Caribbean \& Central America

North America West Coast to/from East China Sea

North America West Coast to/from Indian Subcontinent

North America West Coast to/from Mediterranean

North America West Coast to/from North America East Coast 
North America West Coast to/from North America West Coast

North Asia to/from Arabian Gulf

North Asia to/from Australasia \& Oceania

North Asia to/from Caribbean \& Central America

North Asia to/from East Africa

North Asia to/from East China Sea

North Asia to/from Indian Subcontinent

North Asia to/from Mediterranean

North Asia to/from North America East Coast

North Asia to/from North America West Coast

North Asia to/from North Asia

North Europe to/from Arabian Gulf

North Europe to/from Atlantic Islands

North Europe to/from Australasia \& Oceania

North Europe to/from Caribbean \& Central America

North Europe to/from East Africa

North Europe to/from East China Sea

North Europe to/from Indian Subcontinent

North Europe to/from Mediterranean

North Europe to/from North America East Coast

North Europe to/from North America West Coast

North Europe to/from North Asia

North Europe to/from North Europe

Red Sea to/from Arabian Gulf

Red Sea to/from Caribbean \& Central America

Red Sea to/from East Africa

Red Sea to/from East China Sea

Red Sea to/from Indian Subcontinent

Red Sea to/from Mediterranean

Red Sea to/from North America East Coast

Red Sea to/from North America West Coast

Red Sea to/from North Asia

Red Sea to/from North Europe

Red Sea to/from Red Sea

South Africa to/from Arabian Gulf

South Africa to/from Atlantic Islands

South Africa to/from Caribbean \& Central America

South Africa to/from East Africa

South Africa to/from East China Sea

South Africa to/from Indian Subcontinent

South Africa to/from Mediterranean

South Africa to/from North America East Coast

South Africa to/from North Asia

South Africa to/from North Europe

South Africa to/from Red Sea 
South Africa to/from South Africa

South America East Coast to/from Caribbean \& Central America

South America East Coast to/from East China Sea

South America East Coast to/from Mediterranean

South America East Coast to/from North America East Coast

South America East Coast to/from North Asia

South America East Coast to/from North Europe

South America East Coast to/from South Africa

South America East Coast to/from South America East Coast

South America West Coast to/from Australasia \& Oceania

South America West Coast to/from Caribbean \& Central America

South America West Coast to/from East China Sea

South America West Coast to/from Mediterranean

South America West Coast to/from North America East Coast

South America West Coast to/from North America West Coast

South America West Coast to/from North Asia

South America West Coast to/from North Europe

South America West Coast to/from South America East Coast

South America West Coast to/from South America West Coast

South China Sea to/from Arabian Gulf

South China Sea to/from Australasia \& Oceania

South China Sea to/from Caribbean \& Central America

South China Sea to/from East Africa

South China Sea to/from East China Sea

South China Sea to/from Indian Subcontinent

South China Sea to/from Mediterranean

South China Sea to/from North America East Coast

South China Sea to/from North America West Coast

South China Sea to/from North Asia

South China Sea to/from North Europe

South China Sea to/from Red Sea

South China Sea to/from South Africa

South China Sea to/from South America East Coast

South China Sea to/from South America West Coast

South China Sea to/from South China Sea

South East Asia to/from Arabian Gulf

South East Asia to/from Australasia \& Oceania

South East Asia to/from Caribbean \& Central America

South East Asia to/from East Africa

South East Asia to/from East China Sea

South East Asia to/from Indian Subcontinent

South East Asia to/from Mediterranean

South East Asia to/from North America East Coast

South East Asia to/from North America West Coast

South East Asia to/from North Asia 
South East Asia to/from North Europe

South East Asia to/from Red Sea

South East Asia to/from South Africa

South East Asia to/from South America East Coast

South East Asia to/from South China Sea

South East Asia to/from South East Asia

West Africa to/from Arabian Gulf

West Africa to/from Atlantic Islands

West Africa to/from East Africa

West Africa to/from East China Sea

West Africa to/from Indian Subcontinent

West Africa to/from Mediterranean

West Africa to/from North America East Coast

West Africa to/from North Asia

West Africa to/from North Europe

West Africa to/from South Africa

West Africa to/from South America East Coast

West Africa to/from South China Sea

West Africa to/from South East Asia

West Africa to/from West Africa

Yellow Sea to/from Arabian Gulf

Yellow Sea to/from Australasia \& Oceania

Yellow Sea to/from Caribbean \& Central America

Yellow Sea to/from East Africa

Yellow Sea to/from East China Sea

Yellow Sea to/from Indian Subcontinent

Yellow Sea to/from Mediterranean

Yellow Sea to/from North America East Coast

Yellow Sea to/from North America West Coast

Yellow Sea to/from North Asia

Yellow Sea to/from North Europe

Yellow Sea to/from Red Sea

Yellow Sea to/from South Africa

Yellow Sea to/from South America East Coast

Yellow Sea to/from South America West Coast

Yellow Sea to/from South China Sea

Yellow Sea to/from South East Asia

Yellow Sea to/from West Africa

Yellow Sea to/from Yellow Sea

Acknowledgements The authors would like to thank the two anonymous reviewers, Jan Hoffmann (UNCTAD), James Mancini (OECD), Pedro Caro de Sousa (OECD), as well as journal Editor-in-Chief Prof. Hercules Haralambides for their comments and suggestions which greatly improved the manuscript. Views expressed here are personal and do not necessarily reflect those of ITF/OECD or MDS Transmodal. 


\section{References}

Bresnahan, Timothy, and Steven Salop. 1986. Quantifying the competitive effects of production joint ventures. International Journal of Industrial Organization 4 (2): 155-175.

Cafruny, A. 1987. Ruling the waves: The political economy of international shipping. Berkeley: University of California Press.

EC. 2004. Guidelines on the assessments of horizontal mergers under the Council Regulation on the control of concentrations between undertakings, 2004/C 31/03. Brussels: European Commission.

EC. 2009. Commission Regulation (EC) No 906/2009 of 28 September 2009 on the application of Article 101(3) of the Treaty to certain categories of agreements, decisions and concerted practices between liner shipping companies (consortia). Brussels: European Commission.

EC. 2016b. Case M.7908 - CMA CGM / NOL, Regulation (EC) No 139/2004 Merger procedure, 29/04/2016b. Brussels: European Commission.

EC. 2016a. Case M.8120 - Hapag-Lloyd/United Arab Shipping Company, Regulation (EC) No. 139/2004 Merger procedure, 23/11/2016a. Brussels: European Commission.

EC. 2017b. Case M.8330 - Maersk Line/HSDG, Regulation (EC) No 139/2004 Merger procedure, 10/04/2017b. Brussels: European Commission.

EC. 2017a. Case M.8594 - Cosco Shipping/OOIL, Regulation (EC) No 139/2004 Merger procedure, 05/12/2017a. Brussels: European Commission.

EC. 2019. Commission Staff Working Document Evaluation of the Commission Regulation (EC) No. $906 / 2009$ of 28 September 2009 on the application of Article 81(3) of the Treaty to certain categories of agreements, decisions and concerted practices between liner shipping companies (consortia), SWD(2019) 412 final. Brussels: European Commission.

Goulielmos, A. 2017. "Containership Markets": A Comparison with Bulk Shipping and a Proposed Oligopoly Model. SPOUDAI Journal of Economics and Business 67 (2): 47-68.

Ha, Y., and J. Seo. 2013. An analysis of market concentration in the Korean liner shipping industry. The Asian Journal of Shipping and Logistics 29 (2): 249-266.

Haralambides, H. 2019. Gigantism in container shipping, ports and global logistics: A time-lapse into the future. Maritime Economics \& Logistics 21: 1-60.

Hirata, E. 2017. Contestability of container liner shipping market in alliance era. The Asian Journal of Shipping and Logistics 33 (1): 27-32.

Hoffmann, J., and J. Hoffmann. 2021. Bigger ships and fewer companies: Two Sides of the same coin? UNCTAD Transport and Trade Facilitation Newsletter No. 89. https://unctad.org/news/bigger-shipsand-fewer-companies-two-sides-same-coin.

ITF. 2018. The impact of alliances in container shipping, International Transport Forum. Paris: OECD.

ITF. 2019. Container shipping: Data for the evaluation of the EU Consortia Block Exemption Regulation, International Transport Forum. Paris: OECD.

Luo, M., L. Fan, and W. Wilson. 2014. Firm growth and market concentration in liner shipping. Journal of Transport Economics and Policy 48 (1): 171-187.

Marx, D. 1953. International shipping cartels: A study of industrial self-regulation by shipping conferences. Princeton: Princeton University Press.

O'Brien, Daniel, and Steven Salop. 2015. Competitive effects of partial ownership: Financial interest and corporate control. Antitrust Law Journal 67 (3): 559-614.

OECD. 2002. Competition policy in liner shipping; final report. Paris: OECD.

OECD. 2017. Common ownership by institutional investors and its impact on competition, background note by the Secretariat. Paris: OECD.

Ortiz Blanco, L. 2007. Shipping conferences under EC Antitrust Law: Criticism of a legal paradox. Oregon: Hart Publishing.

Sys, C. 2009. Is the container liner shipping industry an oligopoly? Transport Policy 16 (5): 259-270.

US Department of Justice and Federal Trade Commission. 2010. Horizontal Merger Guidelines. https:// www.justice.gov/atr/horizontal-merger-guidelines-08192010\#5c.

Publisher's Note Springer Nature remains neutral with regard to jurisdictional claims in published maps and institutional affiliations. 


\section{Authors and Affiliations}

\section{Olaf Merk ${ }^{1} \cdot$ Antonella Teodoro $^{2}$}

$\triangle$ Olaf Merk

olaf.merk@itf-oecd.org

1 International Transport Forum (ITF), Organisation for Economic Co-operation and Development (OECD), 2 rue André Pascal, 75016 Paris, France

2 MDS Transmodal, 5-6 Hunters Walk, Canal Street, Chester CH1 4 EB, UK 